\title{
Non-alcoholic fatty liver disease among patients with sleep disorders: a Nationwide study of Taiwan
}

\author{
Yu-Ting Wei ${ }^{1,2,3,4,5}$, Peng-Yi Lee ${ }^{6,7 \dagger}$, Cheng-Yu Lin ${ }^{1,8,9}$, Hsuan-Ju Chen ${ }^{10,11}$, Che-Chen Lin ${ }^{10,12}$, Jin-Shang Wu ${ }^{3,13}$, \\ Yin-Fan Chang ${ }^{3}$, Chen-Long Wu $\mathrm{W}^{2,14^{*}}$ and How-Ran Guo ${ }^{1,2,4,14^{*}}$ (i)
}

\begin{abstract}
Background: Nonalcoholic fatty liver disease (NAFLD) is one of the most common chronic liver diseases. Studies have shown that sleep apnea is associated with NAFLD. However, studies on the association between sleep disorders in general and NAFLD are limited. We conducted a nationwide population-based longitudinal study to evaluate this potential association.
\end{abstract}

Methods: We identified patients diagnosed with sleep disorders in the years 2000 through 2005 in Taiwan using the National Health Insurance Research Database and selected an equal number of patients without sleep disorders from the same database as the comparison cohort. The patients were followed from the index date to the diagnosis of NAFLD or the end of 2013. We used Cox proportional hazards models to estimate the risk of NAFLD associated with sleep disorders.

Results: A total of 33,045 patients with sleep disorders were identified. The incidence of NAFLD was 14.0 per 10,000 person-year in patients with sleep disorders and 6.2 per 10,000 person-year in the comparison cohort. The adjusted hazard ratio (AHR) of NAFLD associated with sleep disorders was 1.78 (95\% confidence interval [95\%Cl]: 1.46-2.16), and other independent risk factors included male sex ( $A H R=1.31,95 \% \mathrm{Cl}: 1.12-1.54)$, age 40-59 years (AHR $=1.49$, 95\%Cl: 1.21-1.82), and dyslipidemia (AHR $=2.51,95 \% \mathrm{Cl}: 2.08-3.04)$. In the subgroup analyses, both patients with $(\mathrm{AHR}=2.24,95 \% \mathrm{Cl}: 1.05-4.77)$ and without (AHR $=1.77,95 \% \mathrm{Cl}: 1.46-2.15)$ sleep apnea had an increased risk of NAFLD.

Conclusions: Sleep disorders are associated with NAFLD, even in patients without sleep apnea. Further studies are warranted to explore the mechanisms of the association.

Keywords: Epidemiology, Sleep disorders, Nonalcoholic fatty liver disease, Population-based cohort study

\section{Background}

Nonalcoholic fatty liver disease (NAFLD) is a rapidly growing public health threat globally. NAFLD is believed to be a hepatic border of metabolic syndrome and is associated with many metabolic changes such as insulin resistance. The proposed mechanisms of NAFLD include

\footnotetext{
* Correspondence: clwu@mail.ncku.edu.tw; hrguo@mail.ncku.edu.tw ${ }^{+}$Yu-Ting Wei and Peng-Yi Lee contributed equally to this work.

2Department of Occupational and Environmental Medicine, National Cheng Kung University Hospital, College of Medicine, National Cheng Kung University, No.138, Sheng Li Road, Tainan 70403, Taiwan, Republic of China 'Department of Environmental and Occupational Health, College of Medicine, National Cheng Kung University, No.138, Sheng Li Road, Tainan 70403, Taiwan, Republic of China

Full list of author information is available at the end of the article
}

predisposition and intake of higher energy, which result in liver damages ranging from steatosis to nonalcoholic steatohepatitis, advanced fibrosis, and eventually, cirrhosis $[1,2]$. The prevalence of NAFLD in the general population is 20 to $30 \%$ in the Western world [3], and 5 to $40 \%$ across the Asia-Pacific region [4-6]. NAFLD is also an emerging liver disease in Taiwan, with prevalence ranging from 11.4 to $41 \%$ [7].

Sleep apnea is a kind of sleep disorders (SD). It refers to momentary, often cyclical, cessations in breathing rhythm, sufficient to cause significant arterial hypoxemia and hypercapnia [8]. Many studies have been conducted on the association between sleep apnea and NAFLD, and the pooled odds ratios were approximately 2 to 3 in

(c) The Author(s). 2020 Open Access This article is distributed under the terms of the Creative Commons Attribution 4.0 International License (http://creativecommons.org/licenses/by/4.0/), which permits unrestricted use, distribution, and reproduction in any medium, provided you give appropriate credit to the original author(s) and the source, provide a link to the Creative Commons license, and indicate if changes were made. The Creative Commons Public Domain Dedication waiver (http://creativecommons.org/publicdomain/zero/1.0/) applies to the data made available in this article, unless otherwise stated. 
meta-analyses [9, 10]. However, sleep apnea constitutes only a portion of sleep disturbance. SD, including short sleep duration, poor sleep quality, etc. [11, 12], are common in the general population [13, 14]. For example, more than $25 \%$ of the Taiwanese adults suffer from insomnia [15]. Patients with SD are at increased risks of obesity, insulin resistance, dyslipidemia, hypertension, diabetes mellitus [16], and cardiovascular disease [17], which have all been reported to be associated with NAFLD $[18,19]$.

Studies on the risk of NAFLD associated with SD are limited. Using "sleep disorder" and "non-alcoholic fatty liver disease" as the keywords to search the literature indexed in the PubMed, we found that most of the previous studies were focused on sleep apnea, and all the limited studies on NAFLD associated with SD in general were cross-sectional studies, which may fall prey to the problem of "inverse causation," i.e. NAFLD being a cause instead of an outcome of SD. Therefore, we conducted a longitudinal study to evaluate the association between SD, including sleep apnea, and NAFLD.

\section{Methods}

We conducted a retrospective population-based cohort study in Taiwan using the National Health Insurance system established by the Taiwanese government in 1995, which covers nearly all Taiwanese citizens. The National Health Insurance Research Database 2000 (NHIRD 2000) contains medical claim data from one million beneficiaries who were randomly selected in 2000. The cohort members have been followed up since the construction of the database, which included the registry of beneficiaries, disease registry profile, drug prescriptions, and other medical services. The disease registry profile recorded the disease history for each insured individual according to the International Classification of Diseases, Ninth Revision, Clinical Modification (ICD-9-CM). The database underwent de-identification before it was released for research use.

The target cohort are those who had SD (defined by having ICD-9-CM 307.4 or 780.5 among the diagnoses on the claims) for at least three consecutive months from 2000 to 2005. The index date of an SD patient was defined as the first diagnosis date. The same number of beneficiaries as those in the SD cohort were randomly selected from those who did not have SD from the same database as the comparison cohort. We excluded candidates who were under 20 years of age and who had a history of NAFLD (ICD-9-CM 571.8), liver cirrhosis (ICD9-CM 571.2, 571.5, or 571.6), hepatitis B (ICD-9-CM V02.61, $070.20,070.22,070.30$, or 070.32 ), hepatitis $C$ (ICD-9-CM V02.62, 070.41, 070.44, 070.51, or 070.54), organic sleep disorders (ICD-9-CM 327), or narcolepsy (ICD-9-CM 347) before the index date. Both cohorts were followed up from the index date to the date when NAFLD was diagnosed or the end of 2013.

To control potential confounding factors, we collected data on diabetes (ICD-9-CM 250), dyslipidemia (ICD-9CM 272), hypertension (ICD-9-CM 401-405), ischemic heart disease (IHD; ICD-9-CM 410-414), depression (ICD-9-CM 296.2, 296.3, 300.4, or 311), and anxiety (ICD-9-CM 300).

We present continuous variables as mean \pm standard deviation and categorical variables as number (percentage). Differences in categorical variables between groups were evaluated using Pearson's chi-square tests, and Student's t-tests were used to evaluate differences in continuous variables. The incidence rate (IR) of NAFLD was calculated as the number of events divided by the person-year observed. We further plotted the cumulative incidence curves for the SD and compared the two cohorts using the Kaplan-Meier method. The log-rank test was used to evaluate the difference.

We used Cox proportional hazards regression models to obtain the hazard ratios (HRs) associated with SD. Univariate analyses were followed by multivariate analyses adjusting for sex, age, and comorbidities, including diabetes mellitus, dyslipidemia, hypertension, ischemic heart disease (IHD), depression, and anxiety. Furthermore, we divided the SD cohort into two subgroups, the sleep apnea group (ICD-9-CM 780.51, 780.53, or 780.57) and the non-apnea group (ICD-9-CM 307.4, 780.50, $780.52,780.54,780.55,780.56$, or 780.59$)$, and conducted analyses separately.

In all statistical tests, the significant level was set at 0.05 (two-tailed). All statistical analyses were performed using the SAS 9.4 software (SAS Institute, Cary, NC, USA) or the $\mathrm{R}$ software. Our study protocol was reviewed and approved by the Ethics Review Board of the China Medical University Hospital (CMUH104REC2-115).

\section{Results}

A total of 33,045 patients were included in the SD cohort, and therefore the comparison cohort also had 33, 045 members. The proportion of men was $39.7 \%$ in the SD cohort and $57.6 \%$ in the comparison cohort $(p<$ 0.001) (Table 1). The mean age of the SD cohort was 12.3 years older than that of the comparison cohort (53.6 vs. 41.3 years, $p<0.001$ ). The prevalence rates of the comorbidities of diabetes mellitus, dyslipidemia, hypertension, IHD, depression, and anxiety were all significantly higher in the SD cohort than those in the comparison cohort (all $p<0.001$ ).

The IR of NAFLD was 14.0 per 10,000 person-year in the SD cohort and was only 6.2 per 10,000 person-year in the comparison cohort. The HR was 2.26 (95\% confidence interval [95\% CI]: $1.92-2.67)$ in the SD cohort 
Table 1 Baseline demographic factors and comorbidities of study participants according to sleep disorder status

\begin{tabular}{|c|c|c|c|c|c|}
\hline \multirow{3}{*}{ Characteristics } & \multicolumn{2}{|c|}{ Comparison Cohort } & \multicolumn{2}{|c|}{ Sleep Disorder Cohort } & \multirow{3}{*}{$p$-value } \\
\hline & \multicolumn{2}{|c|}{$(N=33,045)$} & \multicolumn{2}{|c|}{$(N=33,045)$} & \\
\hline & $\mathrm{N}$ & $\%$ & $\mathrm{~N}$ & $\%$ & \\
\hline Sex & & & & & $<0.001$ \\
\hline Women & 14,002 & 42.4 & 19,937 & 60.3 & \\
\hline Men & 19,043 & 57.6 & 13,108 & 39.7 & \\
\hline Age (year) & & & & & $<0.001$ \\
\hline 20-39 & 17,696 & 53.6 & 7582 & 22.9 & \\
\hline $40-59$ & 10,817 & 32.7 & 13,271 & 40.2 & \\
\hline$\geq 60$ & 4532 & 13.7 & 12,192 & 36.9 & \\
\hline Mean (standard deviation) & 41.3 & $(15.6)$ & 53.6 & $(16.5)$ & $<0.001^{\mathrm{b}}$ \\
\hline \multicolumn{6}{|l|}{ Comorbidities } \\
\hline Diabetes & 1529 & 4.6 & 4816 & 14.6 & $<0.001$ \\
\hline Dyslipidemia & 2451 & 7.4 & 8474 & 25.6 & $<0.001$ \\
\hline Hypertension & 4231 & 12.8 & 14,476 & 43.8 & $<0.001$ \\
\hline Ischemic Heart Disease & 1659 & 5.0 & 8176 & 24.7 & $<0.001$ \\
\hline Depression & 218 & 0.7 & 4111 & 12.4 & $<0.001$ \\
\hline Anxiety disorder & 1120 & 3.4 & 12,870 & 39.0 & $<0.001$ \\
\hline
\end{tabular}

${ }^{\mathrm{a} C h i-s q u a r e ~ t e s t, ~ u n l e s s ~ o t h e r w i s e ~ n o t e d ; ~}{ }^{\mathrm{b}}$ Student's t-test

with the comparison cohort as the reference (Table 2). After adjusting for age, sex, and comorbidities (diabetes, dyslipidemia, hypertension, IHD, depression, and anxiety), we found that patients with SD had an increased risk of developing NAFLD, with an adjusted HR (AHR) of 1.78 (95\% CI: 1.46-2.15). In addition, there were significant higher risks associated with male sex $(\mathrm{AHR}=$ 1.31, 95\% CI: $1.12-1.54)$, age $40-59$ years $(\mathrm{AHR}=1.49$, 95\% CI: $1.21-1.82$ ), and dyslipidemia (AHR $=2.51,95 \%$ CI: 2.08-3.04). However, the AHRs associated with diabetes $(\mathrm{AHR}=1.04,95 \% \mathrm{CI}: 0.82-1.33)$ and hypertension (AHR $=1.02,95 \%$ CI: 0.84-1.25) did not reach statistical significance in the multi-variate Cox proportional hazards regression analyses. The cumulative incidence of NAFLD in the SD cohort was significantly higher than that in the comparison cohort $(p<0.001)$ (Fig. 1).

In the stratified analyses (Table 3), the AHR in women was 1.82 (95\% CI: 1.35-2.46), similar to that in men $(\mathrm{AHR}=1.79,95 \% \mathrm{CI}: 1.38-2.32)$. At the age of $20-39$, $40-59$ and $\geq 60$ years, the AHR was 1.71 (95\% CI: 1.18 2.48), 1.89 (95\% CI: 1.44-2.47) and 1.23 (95\% CI: $0.79-$ 1.91), respectively. All the AHRs in the groups without the comorbidity were significantly higher than those in the groups with the comorbidity. Specifically, the AHR was 1.84 (95\% CI: $1.50-2.26)$ in patients without diabetes, 2.10 (95\% CI: 1.67-2.65) in patients without dyslipidemia, 2.03 (95\% CI: 1.61-2.57) in patients without hypertension, 1.88 (95\% CI: 1.53-2.31) in patients without IHD, 1.81 (95\% CI: 1.48-2.20) in patients without depression, and 1.82 (95\% CI: 1.48-2.24) in patients without anxiety. None of the AHRs in the subgroups with those comorbidities reached statistical significance.

Amongst the SD cohort, the sleep apnea group had an increased risk of NAFLD, with an AHR of 2.24 (95\% CI: 1.05-4.77) after adjustment for age, sex, and the comorbidities (Table 4). Nonetheless, the non-apnea group also had an increased risk of NAFLD, with an AHR of 1.77 (95\% CI: 1.46-2.15).

\section{Discussion}

This nationwide retrospective population-based cohort study found that patients with SD had a significantly higher risk of developing NAFLD. The increased risk of NAFLD was observed not only in the subgroups of SD patients with sleep apnea, but also in SD patients without sleep apnea. Previous studies on the association between SD and NAFLD were mostly on sleep apnea. Using "sleep disorder" and "non-alcoholic fatty liver disease" as the key words to search the literature indexed in the PubMed, we found five studies on the association between NAFLD and SD in general. The National Health and Nutrition Examination Survey (NHANES) in 2005 to 2010 in the U.S. found that SD was associated with a 1.4 times higher risk of NAFLD [20]. A study of 69,463 middle-aged Korean workers and their spouses found that short sleep duration and poor sleep quality were significantly associated with an increased risk of NAFLD [21]. A study of 46 patients with biopsy-proven NAFLD and 22 healthy controls also found that in the NAFLD patients, sleep duration was shortened, sleep 
Table 2 Hazard ratios of non-alcoholic fatty liver disease associated with sleep disorders and covariates

\begin{tabular}{|c|c|c|c|c|c|c|c|c|}
\hline \multirow[t]{2}{*}{ Characteristics } & \multirow[t]{2}{*}{ N } & \multirow[t]{2}{*}{ Event } & \multirow{2}{*}{$\begin{array}{l}\text { Person- } \\
\text { year }\end{array}$} & \multirow{2}{*}{$\begin{array}{l}\text { Incidence Rate } \\
\text { (/10,000 person-year) }\end{array}$} & \multicolumn{4}{|c|}{ Hazard Ratio (95\% Confidence Interval) } \\
\hline & & & & & Univariate & $p$-value & Multivariate $^{a}$ & $\overline{p \text {-value }}$ \\
\hline \multicolumn{9}{|l|}{ Sleep disorders } \\
\hline No & 33,045 & 206 & 333,121 & 6.2 & Reference & & Reference & \\
\hline Yes & 33,045 & 441 & 314,627 & 14.0 & $2.26(1.92-2.67)$ & $<0.001$ & $1.78(1.46-2.16)$ & $<0.001$ \\
\hline \multicolumn{9}{|l|}{ Sex } \\
\hline Women & 33,939 & 325 & 337,279 & 9.6 & Reference & & Reference & \\
\hline Men & 32,151 & 322 & 310,470 & 10.4 & $1.08(0.92-1.26)$ & 0.35 & $1.31(1.12-1.54)$ & $<0.001$ \\
\hline \multicolumn{9}{|l|}{ Age (year) } \\
\hline 20-39 & 25,278 & 166 & 260,647 & 6.4 & Reference & & Reference & \\
\hline $40-59$ & 24,088 & 337 & 245,204 & 13.7 & $2.16(1.79-2.60)$ & $<0.001$ & $1.49(1.21-1.82)$ & $<0.001$ \\
\hline$\geq 60$ & 16,724 & 144 & 141,898 & 10.2 & $1.59(1.27-1.99)$ & $<0.001$ & $0.86(0.66-1.13)$ & 0.28 \\
\hline \multicolumn{9}{|l|}{ Comorbidities } \\
\hline \multicolumn{9}{|l|}{ Diabetes } \\
\hline No & 59,745 & 556 & 592,827 & 9.4 & Reference & & Reference & \\
\hline Yes & 6345 & 91 & 54,922 & 16.6 & $1.77(1.41-2.20)$ & $<0.001$ & $1.04(0.82-1.33)$ & 0.73 \\
\hline \multicolumn{9}{|l|}{ Dyslipidemia } \\
\hline No & 55,165 & 411 & 544,066 & 7.6 & Reference & & Reference & \\
\hline Yes & 10,925 & 236 & 103,683 & 22.8 & $3.01(2.56-3.53)$ & $<0.001$ & $2.51(2.08-3.04)$ & $<0.001$ \\
\hline \multicolumn{9}{|c|}{ Hypertension } \\
\hline No & 47,383 & 407 & 479,123 & 8.5 & Reference & & Reference & \\
\hline Yes & 18,707 & 240 & 168,625 & 14.2 & $1.68(1.43-1.97)$ & $<0.001$ & $1.02(0.84-1.25)$ & 0.83 \\
\hline \multicolumn{9}{|c|}{ Ischemic Heart Disease } \\
\hline No & 56,255 & 529 & 560,892 & 9.4 & Reference & & Reference & \\
\hline Yes & 9835 & 118 & 86,856 & 13.6 & $1.44(1.18-1.76)$ & $<0.001$ & $0.86(0.68-1.08)$ & 0.19 \\
\hline \multicolumn{9}{|l|}{ Depression } \\
\hline No & 61,761 & 574 & 606,799 & 9.5 & Reference & & Reference & \\
\hline Yes & 4329 & 73 & 40,950 & 17.8 & $1.88(1.47-2.40)$ & $<0.001$ & $1.23(0.94-1.62)$ & 0.14 \\
\hline \multicolumn{9}{|l|}{ Anxiety } \\
\hline No & 52,100 & 437 & 514,026 & 8.5 & Reference & & Reference & \\
\hline Yes & 13,990 & 210 & 133,722 & 15.7 & $1.84(1.56-2.17)$ & $<0.001$ & $1.16(0.95-1.42)$ & 0.15 \\
\hline
\end{tabular}

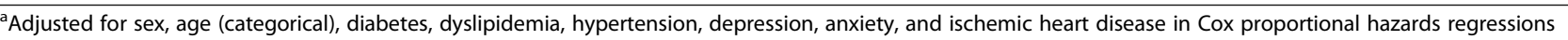

onset was delayed, and sleep quality was poor [22]. A study of 2172 people in Japan found that the prevalence of NAFLD tended to decrease as sleep duration increased in men, but in women, and that it was lowest in the group with a sleep duration of 6 to $\leq 7 \mathrm{~h}$ and highest in the groups with sleep durations of $\leq 6$ and $>8 \mathrm{~h}$ [23]. In younger populations, a study of 708 non-diabetic youngsters found that sleep shortage was associated with the presence of NAFLD [24]. In general, findings in those studies are compatible with our finding of an association between SD and NAFLD.

We observed an AHR of 2.24 for developing NAFLD in the SD patients with sleep apnea, which is consistent with the pooled odds ratios (between 2 and 3) obtained in meta-analyses $[9,10]$. Chronic intermittent hypoxia [25, 26], which has been shown to induce liver steatosis [27], is generally considered as a major mechanism through which sleep apnea leads to NAFLD. Nonetheless, we also observed an increased risk of NAFLD in SD patients without sleep apnea. There should be mechanisms other than chronic intermittent hypoxia through which SD may cause NAFLD. Epidemiologic studies have shown that sleep insufficiency may lead to alternation of glucose homeostasis [28], insulin resistance [29, 30], weight gain [31], obesity [32], metabolic syndrome [33, 34], and diabetes mellitus $[35,36]$, which are all associated with NAFLD [16, 37-39]. In experimental studies, sleep disturbance was found to induce some inflammatory cytokines such as tumor necrosis factor-alpha, 


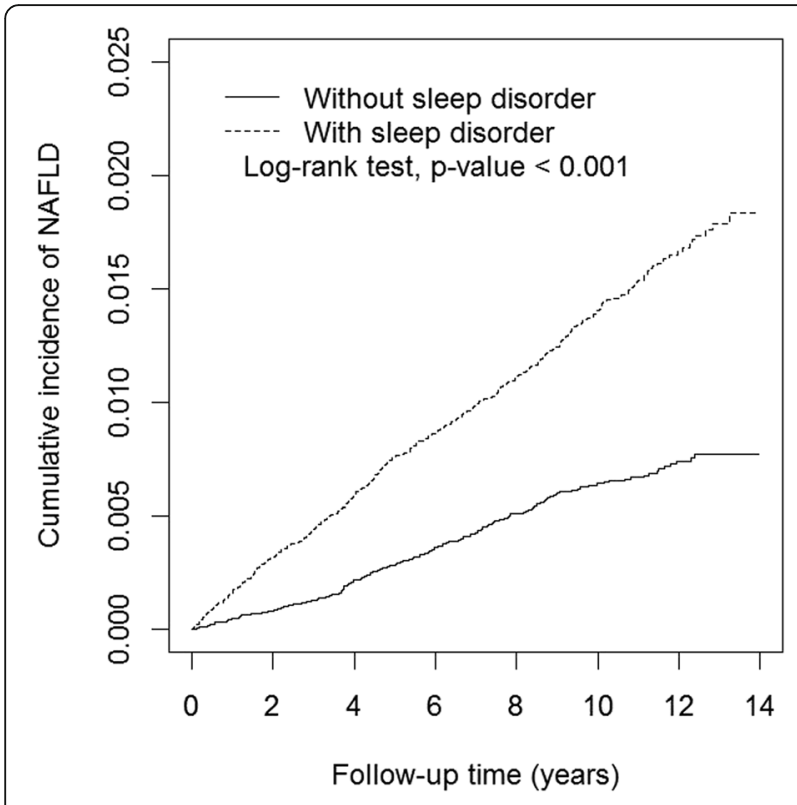

Fig. 1 Cumulative incidence curves of non-alcoholic fatty liver disease for cohorts with and without sleep disorders

interleukin-1 beta, and interleukin-6 [40-42], which play important roles in the pathogenesis of NAFLD [43-45]. Also, sleep loss elevates the level of ghrelin and reduces the level of leptin [46, 47], which increase appetite and further cause obesity. Moreover, chronic insomnia activates the hypothalamo-pituitary-adrenal axis [48], increases stress hormone, worsens insulin resistance, and facilitates the progression of NAFLD [49].

We performed stratified analyses according to most of the generally recognized risk factors for NAFLD, including diabetes mellitus, hypertension, dyslipidemia, depression, and anxiety $[19,50,51]$. The results showed that the effects of SD on the development of NAFLD were significant in patients without these factors, but not in those with these factors. This provided insights that SD may lead to NAFLD through pathways different from those associated with these risk factors and that SD may be a major risk factor for NAFLD in relatively healthy people.

All five of the previous studies on the association between SD and NAFLD that we identified in the literature review adopted cross-sectional study designs. With a longitudinal study design, our study has the advantage of providing stronger evidence of causation in terms of temporal relationship. In addition, most of the previous studies used questionnaires to define SD, and the diagnosis of NAFLD was not confirmed by a physician in all the cases. In the NHANES study [20], for example, the diagnosis of SD was established by questionnaires, and NAFLD was defined as elevated liver enzymes without chronic hepatitis $\mathrm{B}$, chronic hepatitis $\mathrm{C}$, or alcoholic liver disease. In our study, all the diagnoses of SD and NAFLD were made by physicians and subject to routine audits by specialists hired by the National Health Insurance. Furthermore, our study also has the advantage of controlling most of the major potential confounders, including sex, age, and comorbidities of diabetes, hypertension, dyslipidemia, IHD, depression, and anxiety at the same time, which had not been achieved in previous studies. As a result, in addition to SD, we identified male sex, age between 40 and 59 years old, and dyslipidemia as independent risk factors for NAFLD. Because SD and NAFLD are exceedingly common in the general population, we suggest screening programs for NAFLD in patients of SD with above factors.

Our study also has some limitations. First, our study included SD patients who chose to seek medical aid, and therefore the results may not be generalized to the patients who do not seek medical aid. A common reason why SD patients do not seek medical aid is that the illness is not severe. However, studying only the patients who were diagnosed by physicians ensured the accuracy of diagnoses, which is regarded as a strength of our study. Second, although obesity is a well-established risk factor for NAFLD, we were unable to evaluate its effects because the number of patients coded with ICD-9-CM 278 in the NHIRD2000 was small. Again, this was due to the fact that not all patients of obesity would seek medical aids. Nonetheless, we included diabetes, hypertension, and IHD in the analyses, and these conditions are major outcomes of obesity. In other words, the effects of obesity were adjusted indirectly to a certain degree in our analyses. Third, NHIRD2000 does not contain information on sleep pattern, duration, and quality. Therefore, we were unable to study the effects of SD in greater details.

\section{Conclusions}

In this nationwide population-based cohort study, patients with SD had a higher risk of developing NAFLD, including those SD patients who did not have sleep apnea. The association was observed in the subgroups without comorbidities of diabetes, dyslipidemia, hypertension, IHD, depression, or anxiety, but was not observed in the patients who had these comorbidities. This finding indicates that SD may lead to NAFLD through pathways that do not involve these previously recognized risk factors. Further studies are warranted to explore these pathways. 
Table 3 Incidence rates and hazard ratios of non-alcoholic fatty liver disease according to sleep disorder status

\begin{tabular}{|c|c|c|c|c|c|c|c|c|c|c|}
\hline \multirow{3}{*}{ Characteristics } & \multirow{2}{*}{\multicolumn{3}{|c|}{ Comparison Cohort }} & \multirow{2}{*}{\multicolumn{3}{|c|}{ Sleep Disorder Cohort }} & \multirow{2}{*}{\multicolumn{4}{|c|}{$\begin{array}{l}\text { Compared to the Comparison Cohort } \\
\text { Hazard Ratio (95\% Confidence Interval) }\end{array}$}} \\
\hline & & & & & & & & & & \\
\hline & Event & Person-year & $\mathrm{IR}$ & Event & Person-year & IR & Crude & $p$-value & Adjusted $^{a}$ & $p$-value \\
\hline \multicolumn{11}{|l|}{ Sex } \\
\hline Women & 65 & 142,160 & 4.6 & 260 & 195,118 & 13.3 & $2.92(2.22-3.83)$ & $<0.001$ & $1.82(1.35-2.46)$ & $<0.001$ \\
\hline Men & 141 & 190,961 & 7.4 & 181 & 119,509 & 15.2 & $2.04(1.64-2.54)$ & $<0.001$ & $1.79(1.38-2.32)$ & $<0.001$ \\
\hline \multicolumn{11}{|l|}{ Age (year) } \\
\hline 20-39 & 88 & 183,841 & 4.8 & 78 & 76,805 & 10.2 & $2.11(1.55-2.86)$ & $<0.001$ & $1.71(1.18-2.48)$ & 0.004 \\
\hline $40-59$ & 89 & 111,058 & 8.0 & 248 & 134,146 & 18.5 & $2.31(1.81-2.94)$ & $<0.001$ & $1.89(1.44-2.47)$ & $<0.001$ \\
\hline$\geq 60$ & 29 & 38,222 & 7.6 & 115 & 103,676 & 11.1 & $1.46(0.97-2.20)$ & 0.07 & $1.23(0.79-1.91)$ & 0.35 \\
\hline \multicolumn{11}{|l|}{ Comorbidities } \\
\hline \multicolumn{11}{|l|}{ Diabetes } \\
\hline No & 186 & 320,194 & 5.8 & 370 & 272,633 & 13.6 & $2.34(1.96-2.79)$ & $<0.001$ & $1.84(1.50-2.26)$ & $<0.001$ \\
\hline Yes & 20 & 12,927 & 15.5 & 71 & 41,995 & 16.9 & $1.11(0.68-1.82)$ & 0.68 & $1.17(0.68-1.99)$ & 0.57 \\
\hline \multicolumn{11}{|l|}{ Dyslipidemia } \\
\hline No & 153 & 309,909 & 4.9 & 258 & 234,156 & 11.0 & $2.24(1.83-2.73)$ & $<0.001$ & $2.10(1.67-2.65)$ & $<0.001$ \\
\hline Yes & 53 & 23,212 & 22.8 & 183 & 80,471 & 22.7 & $0.99(0.74-1.36)$ & 0.99 & $1.03(0.74-1.44)$ & 0.85 \\
\hline \multicolumn{11}{|l|}{ Hypertension } \\
\hline No & 157 & 295,681 & 5.3 & 250 & 183,442 & 13.6 & $2.56(2.10-3.13)$ & $<0.001$ & $2.03(1.61-2.57)$ & $<0.001$ \\
\hline Yes & 49 & 37,440 & 13.1 & 191 & 131,186 & 14.6 & $1.12(0.82-1.53)$ & 0.49 & $1.09(0.78-1.52)$ & 0.61 \\
\hline \multicolumn{11}{|c|}{ Ischemic heart disease } \\
\hline No & 190 & 319,112 & 6.0 & 339 & 241,780 & 14.0 & $2.35(1.97-2.81)$ & $<0.001$ & $1.88(1.53-2.31)$ & $<0.001$ \\
\hline Yes & 16 & 14,009 & 11.4 & 102 & 72,847 & 14.0 & $1.23(0.73-2.09)$ & 0.44 & $1.04(0.60-1.82)$ & 0.88 \\
\hline \multicolumn{11}{|l|}{ Depression } \\
\hline No & 203 & 331,189 & 6.1 & 371 & 275,610 & 13.5 & $2.19(1.85-2.60)$ & $<0.001$ & $1.81(1.48-2.20)$ & $<0.001$ \\
\hline Yes & 3 & 1932 & 15.5 & 70 & 39,017 & 17.9 & $1.16(0.37-3.68)$ & 0.80 & $0.99(0.31-3.17)$ & 0.98 \\
\hline \multicolumn{11}{|l|}{ Anxiety } \\
\hline No & 191 & 322,595 & 5.9 & 246 & 191,432 & 12.9 & $2.17(1.79-2.62)$ & $<0.001$ & $1.82(1.48-2.24)$ & $<0.001$ \\
\hline Yes & 15 & 10,526 & 14.3 & 195 & 123,196 & 15.8 & $1.11(0.66-1.88)$ & 0.69 & $1.04(0.61-1.77)$ & 0.88 \\
\hline
\end{tabular}

IR Incidence rate per 10,000 person-year

a'Model mutually adjusted for sex, age (categorical), diabetes, dyslipidemia, hypertension, depression, anxiety, and ischemic heart disease

Table 4 Incidence rates and hazard ratios of non-alcoholic fatty liver disease in different subgroups

\begin{tabular}{|c|c|c|c|c|c|c|c|c|}
\hline \multirow[t]{2}{*}{ Subgroup } & \multirow[t]{2}{*}{ N } & \multirow[t]{2}{*}{ Event } & \multirow[t]{2}{*}{ Person-year } & \multirow{2}{*}{$\begin{array}{l}\text { Incidence Rate } \\
(/ 10,000 \text { person-year })\end{array}$} & \multicolumn{4}{|c|}{ Hazard Ratio (95\% Confidence Interval) } \\
\hline & & & & & Crude & $p$-value & Adjusted $^{a}$ & $p$-value \\
\hline Comparison Cohort & 33,045 & 206 & 333,121 & 6.2 & Reference & & Reference & \\
\hline \multicolumn{9}{|l|}{ Sleep Disorder Cohort } \\
\hline Apnea Group & 388 & 7 & 3751 & 18.7 & $3.01(1.42-6.39)$ & 0.004 & $2.24(1.05-4.77)$ & 0.04 \\
\hline Non-apnea Group & 32,657 & 434 & 310,877 & 14.0 & $2.25(1.91-2.66)$ & $<0.001$ & $1.77(1.46-2.15)$ & $<0.001$ \\
\hline
\end{tabular}




\section{Abbreviations}

AHR: Adjusted hazard ratio; HR: Hazard ratio; ICD-9-CM: International Classification of Diseases, Ninth Revision, Clinical Modification; IHD: Ischemic heart disease; IR: Incidence rate; NAFLD: Nonalcoholic fatty liver disease: NHANES: National Health and Nutrition Examination Survey; NHIRD: National Health Insurance Research Database; SD: Sleep disorders

\section{Acknowledgements}

The authors would like to thank the Ministry of Health and Welfare, Taiwan, R.O.C., China Medical University Hospital, Academia Sinica, Taiwan, R.O.C., Ministry of Science and Technology Taiwan, R.O.C., Tseng-Lien Lin Foundation, Ministry of Education, Taiwan, R.O.C., and Katsuzo and Kiyo Aoshima Memorial Funds, Japan for their funding supports.

\section{Authors' contributions}

The contributions of the authors of this paper are as following: Y-TW, P-YL, C-YL, J-SW, Y-FC, and H-RG conceived the study; Y-TW, P-YL, and C-LW designed the study; and $\mathrm{H}-J \mathrm{C}$ and $\mathrm{C}-\mathrm{CL}$ performed statistical analysis. Y-TW, P$Y L, C-L W$, and H-RG drafted the manuscript, and all authors read and approved the final manuscript.

\section{Funding}

This work was supported by grants from the Ministry of Health and Welfare, Taiwan, R.O.C. (Grant Number: MOHW107-TDU-B-212-123004); China Medical University Hospital; Academia Sinica, Taiwan, R.O.C. (BM10701010021; Stroke Biosignature Project); Ministry of Science and Technology Taiwan, R.O.C. (MOST 106-2321-B-039-005; Clinical Trial Consortium for Stroke); Tseng-Lien Lin Foundation, Taichung, Taiwan; Ministry of Education, Taiwan, R.O.C. Headquarters of University Advancement to the National Cheng Kung University; and Katsuzo and Kiyo Aoshima Memorial Funds, Japan. The funders had no role in the design of the study and collection, analysis, and interpretation of data and in writing the manuscript.

\section{Availability of data and materials}

The data is from the National Health Insurance Research Database (NHIRD), which has been transferred to the Health and Welfare Data Science Center (HWDC). Researchers can apply for the data via HWDC, Department of Statistics, Ministry of Health and Welfare, Taiwan (http://dep.mohw.gov.tw/ DOS/np-2497-113.html)

\section{Ethics approval and consent to participate}

Our study protocol was reviewed and approved by the Ethics Review Board of the China Medical University Hospital (CMUH104-REC2-115) in 2015.

\section{Consent for publication}

Not Applicable.

\section{Competing interests}

The authors declare that they have no competing interests.

\section{Author details}

'Department of Environmental and Occupational Health, College of Medicine, National Cheng Kung University, No.138, Sheng Li Road, Tainan 70403, Taiwan, Republic of China. ${ }^{2}$ Department of Occupational and Environmental Medicine, National Cheng Kung University Hospital, College of Medicine, National Cheng Kung University, No.138, Sheng Li Road, Tainan 70403, Taiwan, Republic of China. ${ }^{3}$ Department of Family Medicine, National Cheng Kung University Hospital, College of Medicine, National Cheng Kung University, No.138, Sheng Li Road, Tainan 70403, Taiwan, Republic of China. ${ }^{4}$ Occupational Safety, Health, and Medicine Research Center, National Cheng Kung University, No.138, Sheng Li Road, Tainan 70403, Taiwan, Republic of China. ${ }^{5}$ Preventive Medicine Center, Taichung Tzu Chi Hospital, Buddhist Tzu Chi Medical Foundation, No. 88, Sec. 1, Fengxing Road, Taichung 42743 Taiwan, Republic of China. ${ }^{6}$ Department of Radiation Oncology, China Medical University Hospital, No. 2, Yude Road, Taichung 40447, Taiwan, Republic of China. ${ }^{7}$ Department of Radiation Oncology, China Medical University Beigang Hospital, No.123, Sinde Road, Yunlin 65152, Taiwan, Republic of China. ${ }^{8}$ Department of Otolaryngology, National Cheng Kung University Hospital, College of Medicine, National Cheng Kung University, No.138, Sheng Li Road, Tainan 70403, Taiwan, Republic of China. ${ }^{9}$ Sleep Medicine Center, National Cheng Kung University Hospital, College of
Medicine, National Cheng Kung University, No.138, Sheng Li Road, Tainan 70403, Taiwan, Republic of China. ${ }^{10}$ Management Office for Health Data, China Medical University Hospital, No.2, Yude Road, North District, Taichung 40447, Taiwan, Republic of China. ${ }^{11}$ College of Medicine, China Medical University, No.91, Hsueh-Shih Road, Taichung 40402, Taiwan, Republic of China. ${ }^{12}$ Healthcare Service Research Center, Taichung Veterans General Hospital, No.1650 Taiwan Boulevard Sect. 4, Taichung 40705, Taiwan, Republic of China. ${ }^{13}$ Department of Family Medicine, College of Medicine, National Cheng Kung University, No. 1 University Road, Tainan 70101, Taiwan, Republic of China. ${ }^{14}$ Department of Occupational and Environmental Medicine, College of Medicine, National Cheng Kung University, No.138, Sheng Li Road, Tainan 70403, Taiwan, Republic of China.

Received: 21 February 2019 Accepted: 23 January 2020

Published online: 10 February 2020

\section{References}

1. Abenavoli L, Milic N, Di Renzo L, Preveden T, Medić-Stojanoska M, De Lorenzo A. Metabolic aspects of adult patients with nonalcoholic fatty liver disease. World J Gastroenterol. 2016;22(31):7006-16.

2. Mishra A, Younossi ZM. Epidemiology and natural history of non-alcoholic fatty liver disease. J Clin Exp Hepatol. 2012;2(2):135-44.

3. Loomba R, Sanyal AJ. The global NAFLD epidemic. Nat Rev Gastroenterol Hepatol. 2013:10(11):686-90.

4. Masarone M, Federico A, Abenavoli L, Loguercio C, Persico M. Non alcoholic fatty liver: epidemiology and natural history. Rev recent Clin trials. 2014;9(3): 126-33

5. Chitturi S, Farrell GC, George J. Non-alcoholic steatohepatitis in the AsiaPacific region: future shock? J Gastroenterol Hepatol. 2004;19(4):368-74.

6. Farrell GC. Non-alcoholic steatohepatitis: what is it, and why is it important in the Asia-Pacific region? J Gastroenterol Hepatol. 2003;18(2):124-38.

7. Hsu C-S, Kao J-H. Non-alcoholic fatty liver disease: an emerging liver disease in Taiwan. J Formos Med Assoc. 2012;111(10):527-35.

8. Dempsey JA, Veasey SC, Morgan BJ, O'Donnell CP. Pathophysiology of sleep apnea. Physiol Rev. 2010;90:47-112.

9. Sookoian S, Pirola CJ. Obstructive sleep apnea is associated with fatty liver and abnormal liver enzymes: a meta-analysis. Obes Surg. 2013; 23(11):1815-25.

10. Musso G, Cassader M, Olivetti C, Rosina F, Carbone G, Gambino R Association of obstructive sleep apnoea with the presence and severity of non-alcoholic fatty liver disease. A systematic review and meta-analysis. Obes Rev. 2013;14(5):417-31.

11. Kronholm E, Partonen T, Laatikainen T, Peltonen M, Härmä M, Hublin C, et al. Trends in self-reported sleep duration and insomnia-related symptoms in Finland from 1972 to 2005: a comparative review and re-analysis of Finnish population samples. J Sleep Res. 2008;17(1):54-62.

12. Bixler E. Sleep and society: an epidemiological perspective. Sleep Med. 2009; 10:S3-6.

13. Wallander MA, Johansson S, Ruigomez A, Garcia Rodriguez LA, Jones R. Morbidity associated with sleep disorders in primary care: a longitudinal cohort study. Prim Care Companion J Clin Psychiatry. 2007;9(5):338-45.

14. Shapiro CM, Dement WC. ABC of sleep disorders. Impact and epidemiology of sleep disorders. BMJ. 1993; 306 (6892): 1604.

15. Kao CC, Huang CJ, Wang MY, Tsai PS. Insomnia: prevalence and its impact on excessive daytime sleepiness and psychological well-being in the adult Taiwanese population. Qual Life Res. 2008;17(8):1073-80.

16. Tilg H, Moschen AR, Roden M. NAFLD and diabetes mellitus. Nat Rev Gastroenterol Hepatol. 2017;14(1):32-42.

17. Mai E, Buysse DJ. Insomnia: prevalence, impact, pathogenesis, differential diagnosis, and evaluation. Sleep Med Clin. 2008;3(2):167-74.

18. Adams LA, Lindor KD. Nonalcoholic fatty liver disease. Ann Epidemiol. 2007; 17(11):863-9.

19. Byrne CD, Targher G. NAFLD: a multisystem disease. J Hepatol. 2015;62(1): S47-64.

20. Mir HM, Stepanova M, Afendy H, Cable R, Younossi ZM. Association of sleep disorders with nonalcoholic fatty liver disease (NAFLD): a population-based study. J Clin Exp Hepatol. 2013;3(3):181-5.

21. Kim CW, Yun KE, Jung HS, Chang Y, Choi ES, Kwon MJ, et al. Sleep duration and quality in relation to non-alcoholic fatty liver disease in middle-aged workers and their spouses. J Hepatol. 2013;59(2):351-7. 
22. Bernsmeier C, Weisskopf DM, Pflueger MO, Mosimann J, Campana B, Terracciano $L$, et al. Sleep disruption and daytime sleepiness correlating with disease severity and insulin resistance in non-alcoholic fatty liver disease: a comparison with healthy controls. PLoS One. 2015;10(11): e0143293.

23. Imaizumi H, Takahashi A, Tanji N, Abe K, Sato $Y$, Anzai $Y$, et al. The association between sleep duration and non-alcoholic fatty liver disease among Japanese men and women. Obes Facts. 2015;8(4):234-42.

24. Trovato FM, Martines GF, Brischetto D, Catalano D, Musumeci G, Trovato GM. Fatty liver disease and lifestyle in youngsters: diet, food intake frequency, exercise, sleep shortage and fashion. Liver Int. 2016;36(3):427-33.

25. Minville C, Hilleret MN, Tamisier R, Aron-Wisnewsky J, Clement K, Trocme C, et al. Nonalcoholic fatty liver disease, nocturnal hypoxia, and endothelial function in patients with sleep apnea. Chest. 2014;145(3):525-33.

26. Benotti P, Wood GC, Argyropoulos G, Pack A, Keenan BT, Gao X, et al. The impact of obstructive sleep apnea on nonalcoholic fatty liver disease in patients with severe obesity. Obesity. 2016;24(4):871-7.

27. Aron-Wisnewsky J, Pepin JL. New insights in the pathophysiology of chronic intermittent hypoxia-induced NASH: the role of gut-liver axis impairment. Thorax. 2015;70(8):713-5.

28. Byberg S, Hansen AL, Christensen DL, Vistisen D, Aadahl M, Linneberg A et al. Sleep duration and sleep quality are associated differently with alterations of glucose homeostasis. Diabet Med. 2012;29(9):e354-60.

29. Spiegel K, Knutson K, Leproult R, Tasali E, Van Cauter E. Sleep loss: a novel risk factor for insulin resistance and type 2 diabetes. J Appl Physiol. 2005; 99(5):2008-19.

30. Rafalson L, Donahue RP, Stranges S, Lamonte MJ, Dmochowski J, Dorn J, et al. Short sleep duration is associated with the development of impaired fasting glucose: the Western New York health study. Ann Epidemiol. 2010; 20(12):883-9.

31. Patel SR, Hu FB. Short sleep duration and weight gain: a systematic review Obes. 2008;16(3):643-53.

32. Xiao Q, Arem H, Moore SC, Hollenbeck AR, Matthews CE. A large prospective investigation of sleep duration, weight change, and obesity in the NIH-AARP diet and health study cohort. Am J Epidemiol. 2013;178(11):1600-10.

33. Xi B, He D, Zhang M, Xue J, Zhou D. Short sleep duration predicts risk of metabolic syndrome: a systematic review and meta-analysis. Sleep Med Rev. 2014;18(4):293-7.

34. Iftikhar IH, Donley MA, Mindel J, Pleister A, Soriano S, Magalang UJ. Sleep duration and metabolic syndrome. An updated dose-risk metaanalysis. Ann Am Thorac Soc. 2015;12(9):1364-72.

35. Shan Z, Ma H, Xie M, Yan P, Guo Y, Bao W, et al. Sleep duration and risk of type 2 diabetes: a meta-analysis of prospective studies. Diabetes Care. 2015; 38(3):529-37.

36. Cappuccio FP, D'elia L, Strazzullo P, Miller MA. Quantity and quality of sleep and incidence of type 2 diabetes. Diabetes Care. 2010;33(2):414-20.

37. Larter CZ, Chitturi S, Heydet D, Farrell GC. A fresh look at NASH pathogenesis. Part 1: the metabolic movers. J Gastroenterol Hepatol. 2010; 25(4):672-90.

38. Chang Y, Ryu S, Sung E, Woo HY, Cho SI, Yoo SH, et al. Weight gain within the normal weight range predicts ultrasonographically detected fatty liver in healthy Korean men. Gut. 2009;58(10):1419-25.

39. Paschos P, Paletas K. Non alcoholic fatty liver disease and metabolic syndrome. Hippokratia. 2009;13(1):9-19.

40. Prather AA, Marsland AL, Hall M, Neumann SA, Muldoon MF, Manuck SB. Normative variation in self-reported sleep quality and sleep debt is associated with stimulated pro-inflammatory cytokine production. Biol Psychol. 2009;82(1):12-7.

41. Mullington JM, Simpson NS, Meier-Ewert HK, Haack M. Sleep loss and inflammation. Best Pract Res Clin Endocrinol Metab. 2010;24(5):775-84.

42. Hayes $A L, X u F$, Babineau D, Patel SR. Sleep duration and circulating adipokine levels. Sleep. 2011;34(2):147-52.

43. Jarrar MH, Baranova A, Collantes R, Ranard B, Stepanova M, Bennett C, et al. Adipokines and cytokines in non-alcoholic fatty liver disease. Aliment Pharmacol Ther. 2008;27(5):412-21.

44. Wieckowska A, Papouchado BG, Li Z, Lopez R, Zein NN, Feldstein AE. Increased hepatic and circulating interleukin-6 levels in human nonalcoholic steatohepatitis. Am J Gastroenterol. 2008;103(6):1372.

45. Tilg H, Moschen AR. IL-1 cytokine family members and NAFLD: Neglected in metabolic liver inflammation. J Hepatol. 55(5):960-2.
46. Spiegel K, Leproult R, L'Hermite-Balériaux M, Copinschi G, Penev PD, Van Cauter E. Leptin levels are dependent on sleep duration: relationships with sympathovagal balance, carbohydrate regulation, cortisol, and thyrotropin. J Clin Endocrinol Metab. 2004:89(11):5762-71.

47. Spiegel K, Tasali E, Leproult R, Scherberg N, Van Cauter E. Twenty-four-hour profiles of acylated and total ghrelin: relationship with glucose levels and impact of time of day and sleep. J Clin Endocrinol Metab. 2010;96(2):486-93.

48. Vgontzas AN, Bixler EO, Lin HM, Prolo P, Mastorakos G, Vela-Bueno A, et al. Chronic insomnia is associated with nyctohemeral activation of the hypothalamic-pituitary-adrenal axis: clinical implications. J Clin Endocrinol Metab. 2001:86(8):3787-94.

49. Mueller KM, Themanns M, Friedbichler K, Kornfeld JW, Esterbauer $\mathrm{H}$, Tuckermann JP, et al. Hepatic growth hormone and glucocorticoid receptor signaling in body growth, steatosis and metabolic liver cancer development. Mol Cell Endocrinol. 2012;361(1):1-11.

50. Saponaro C, Gaggini M, Gastaldelli A. Nonalcoholic fatty liver disease and type 2 diabetes: common pathophysiologic mechanisms. Curr Diab Rep. 2015;15(6):34

51. Youssef NA, Abdelmalek MF, Binks M, Guy CD, Omenetti A, Smith AD, et al. Associations of depression, anxiety and antidepressants with histologica severity of nonalcoholic fatty liver disease. Liver Int. 2013;33(7):1062-70.

\section{Publisher's Note}

Springer Nature remains neutral with regard to jurisdictional claims in published maps and institutional affiliations.
Ready to submit your research? Choose BMC and benefit from:

- fast, convenient online submission

- thorough peer review by experienced researchers in your field

- rapid publication on acceptance

- support for research data, including large and complex data types

- gold Open Access which fosters wider collaboration and increased citations

- maximum visibility for your research: over $100 \mathrm{M}$ website views per year

At $\mathrm{BMC}$, research is always in progress.

Learn more biomedcentral.com/submissions 